\title{
Made-in-Canada accreditation coming for medical schools
}

$\mathrm{F}$ or the first time, Canada will set its own standards for medical school accreditation. The landmark Memorandum of Understanding effectively gives Canadian medical schools the right to set their own educational standards and procedures.

"It's huge," says Dr. Geneviève Moineau, president and chief executive officer of the Association of Faculties of Medicine of Canada (AFMC). "Before, whether we agreed with the LCME [the United States Liaison Committee on Medical Education] standards and processes or not, we had to abide by them. Now we can create our own."

The agreement is the culmination of a two-year negotiation between the LCME and the Committee on Accreditation of Canadian Medical Schools (CACMS). Formalizing a relationship that has existed for more than 50 years, the memorandum was signed Dec. 12 in Washington, DC by the four organizations overseeing medical school accreditation in the US and Canada: the Association of American Medical Colleges, American Medical Association, Canadian Medical Association (CMA) and AFMC.

The made-in-Canada standards will be prepared for June 2014 approval by the LCME.

"It paves the way for the future, continuing close relationship between the two countries' medical accreditation ... while recognizing the Canadian context," said Dr. Brian Brodie, chair of the CMA's Board of Directors.

Accreditation in Canada and the US dates back to the 1910 Flexner Report. Today, the joint accreditation process sets standards and includes peer review and quality assurance for the 134 US medical schools and the 17 in Canada. This joint process allows reciprocity for students and residents.

However, Canada has paid a price for the reciprocity in terms of control. The 131 standards, concerning institutions, curriculum, medical student experience, faculty and resources, as well as procedures, are currently all set by the US.

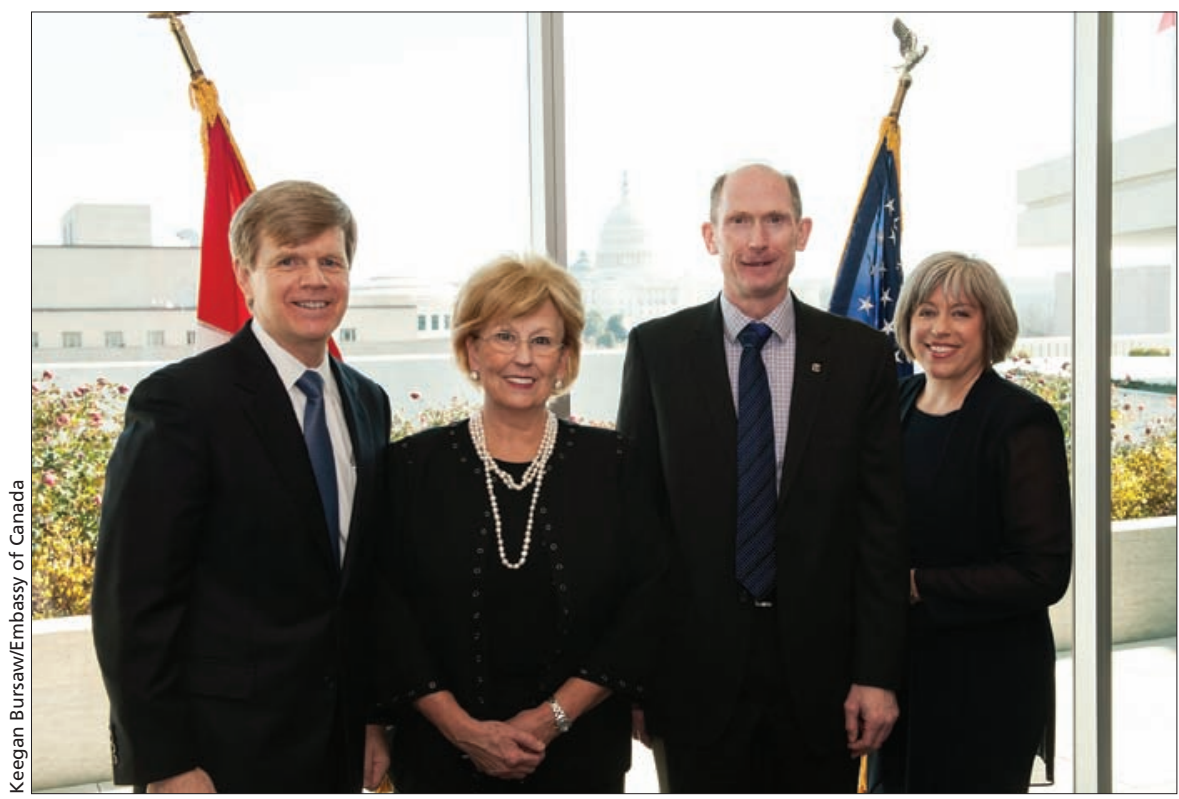

Signatories to the Memorandum of Understanding at the Embassy of Canada in Washington, DC included (left to right) Dr. John E. Prescott, Association of American Medical College's chief academic officer, Dr. Ardis D. Hoven, American Medical Association president, Dr. Brian Brodie, chair of the Canadian Medical Association's Board of Directors and Dr. Geneviève Moineau, president and chief executive officer of the Association of Faculties of Medicine of Canada.

In addition, the US has a say in Canadian accreditation decisions. Both committees received reports about Canadian schools and then rendered decisions separately. These decisions were then compared and the most severe was applied to the school.

"It's like getting two report cards and the worse [one] was the final," said Moineau.

Under the new agreement, Canadian accreditors will review reports, deliberate and make all decisions about Canadian schools. The American LCME will then decide whether to accept the decision. If it doesn't, the case goes to a joint committee, comprised of the chairs of the Canadian and US committees and the chair-elect of the US organization. Its decision is final.

Students and residents will continue to have reciprocity to the US and vice versa, and medical schools will still have dual accreditation. But now CACMS has the right to create its own standards, says Moineau.
"We have moved to a much different level."

In practice what this means, for example, is that the Canadian medical education community can now integrate social accountability into its standards, something that was previously impossible when Canada was bound to US standards. Social accountability in terms of medical school accreditation could mean that part of a school's mission would be to train future physicians to respond to the needs of various communities, such as those in francophone or Northern regions.

In terms of procedures, the agreement formally permits CACMS to include more participation from students, the public and experts outside of medical education on its committees, says Moineau. "A broader scope of individuals involved will improve our process." - Barbara Sibbald, CMAJ

CMAJ 2014. DOI:10.1503/cmaj.109-4692 